\title{
28 Research Square \\ Conditionally Immortalised Equine Skeletal Muscle Cell Lines for in Vitro Analysis
}

Mary Francis Rooney ( $\nabla$ rooneym4@tcd.ie )

Trinity College Dublin

Nuno Neto

Trinity College Dublin

Michael Monaghan

Trinity College Dublin

Emmeline Hill

Plusvital (Ireland)

Richard Porter

Trinity College Dublin

\section{Research Article}

Keywords: Equine, skeletal muscle, cell culture, immortalized cells, coenzyme Q10, bioenergetics, mitochondrial function, myostatin

Posted Date: November 29th, 2021

DOI: https://doi.org/10.21203/rs.3.rs-1039168/v1

License: (c) (i) This work is licensed under a Creative Commons Attribution 4.0 International License.

Read Full License 


\section{Abstract}

\section{Background}

Thoroughbred racehorse performance is largely influenced by a major quantitative trait locus at the myostatin (MSTM) gene which determines aptitude for certain race distances due to a promoter region insertion mutation influencing functional phenotypes in skeletal muscle. To develop an in vitro system for functional experiments we established three novel equine skeletal muscle cell lines reflecting the variation in phenotype associated with MSTN genotype (CC/II, CT/IN and TT/NN for SNP g.66493737C>T/SINE insertion 227 bp polymorphism). Primary equine skeletal muscle myoblasts, isolated from Thoroughbred horse gluteus medius, were conditionally immortalised and evaluated to determine whether cell phenotype and metabolic function were comparable to functional characteristics previously reported for ex vivo skeletal muscle isolated from Thoroughbred horses with each genotype.

\section{Results}

Primary myoblasts conditionally immortalized with the temperature sensitive SV40TtsA58 lentivirus vector successfully proliferated and could revert to their primary cell phenotype and differentiate into multinucleated myotubes. Skeletal muscle fibre type, MSTN gene expression, mitochondrial abundance, and mitochondrial function of the three MSTN genotype cell lines, were consistent with equivalent characterisation of ex vivo skeletal muscle samples with these genotypes. Furthermore, addition of coenzyme $\mathrm{Q}_{10}\left(\mathrm{CoQ}_{10}\right)$ to the cell lines improved mitochondrial function, an observation consistent with ex vivo skeletal muscle samples with these genotypes following supplementation with $\mathrm{CoQ}_{10}$ in the diet.

\section{Conclusions}

The observation that the phenotypic characteristics and metabolic function of the cells lines are equivalent to ex vivo skeletal muscle indicates that this in vitro system will enable efficient and costeffective analyses of equine skeletal muscle for a range of different applications including understanding metabolic function, testing of nutritional supplements, drug test development and gene doping test development. In the multi-billion-euro international Thoroughbred horse industry research advances in the biological function of skeletal muscle are likely to have considerable impact. Furthermore, this novel genotype-specific system may be adapted and applied to human biomedicine to improve understanding of the effects of myostatin in human physiology and medicine.

\section{Background}

The development of cell culture systems for functional studies reduces the need for in vivo experiments while allowing a broader study of cell physiology, disease progression and drug testing [1,2] and provides a cost-effective and ethically prudent approach [3, 4]. Several immortalised mammalian tissue cell lines have been created, particularly as models mimicking cancer or disease (e.g. HeLa, human cervical cancer [5]; MCF-7, human breast cancer [6]; SH-SY5Y, human neuroblastoma [7]). There are fewer immortalized 
cell lines representing the wild-type or unaffected phenotype (e.g. C2C12, mouse skeletal muscle [8]; HEK293, human embryonic kidney cells [9]), for these cell types, researchers frequently use primary cells or tissue when assessing normal cell function. However, working in vivo, with ex vivo tissue samples and working with primary cells, all have their limitations; working in vivo or with ex vivo tissue samples can have logistical challenges, particularly in the field of livestock and large animal research. Thoroughbred horses, for instance, are large, valuable animals who by the nature of their purpose are either in active race training or breeding and are most commonly privately-owned rather than maintained in research herds and therefore regular tissue sampling is challenging. Primary cells, while advantageous due to their close representation of in vivo models, will generally only grow in culture for a limited number of divisions before cell cycle arrest (cellular senescence) [10-12], meaning further tissue sampling would be required to maintain a cell stock. Although some primary cell lines have been capable of extended growth and subsequent use as cell models for functional analysis in vitro, due to spontaneous immortalization [1315], this is not a common occurrence. Immortal cell lines alleviate these limitations by providing a means of prolonged cell growth enabling continuous experimental research. To our knowledge, there is no commercially available immortal equine skeletal muscle cell line, although several laboratories have developed equine fibroblast and skeletal muscle cell lines tailored to specific experimental requirements [16-19].

The Thoroughbred horse industry is a long established highly economically valuable international industry. Novel techniques or experimental assessments that can further research in Thoroughbred physiology for the improved health and wellbeing of these animals will have strong economic bearing. Therefore, we considered that the development of an in vitro immortalised equine cell line would provide considerable potential for refining the understanding of equine skeletal muscle metabolism and for the assessment of nutritional supplements. Research into the benefits of nutritional supplements has been somewhat limited to-date [20-22], potentially due to the cost, and the logistical and ethical constraints of in vivo and ex vivo analysis in these animals. There are also many misconceptions, due to a lack of detailed information on some supplements, meaning consumers are often unaware of the specific benefits and/or the actual efficacy of the supplement they are purchasing [23-25]. This is also the case for humans, where similarly, nutrient supplementation is prevalent, but the research is relatively limited [26-28].

The development of an in vitro model provides a cost-effective and practical system for in vitro testing of the potential benefits of supplements. This could have a huge impact on the supplement industry, by providing scientific evidence on the benefits and the efficiency of nutrients available to consumers. An advantage of the in vitro system will be analysis of specific ingredients contained in multi-nutrient supplements, therefore potentially reducing costs by removing ineffective or unnecessary compounds and in turn reducing the unnecessary substances consumed by the end user. Increasing research efforts on equine supplements will provide consumers with the information they need to make informed choices before using a supplement. Similar research could be applied to supplements for human consumption, either as initial testing in these equine cells with follow up in vivo studies or specific experimentation on a smaller scale with human primary muscle cells. 
In vitro systems can have several other beneficial applications such a tool in gene editing research and for testing the effects of banned substances. Drug doping in the world of equine sports and in the realm of sports in general is constantly evolving and with each new method of doping comes the requirement to find a method of detection. Currently the process of doping testing in horses is complex [29], with little harmonisation across the governing bodies worldwide. Finding ways to cope with the evolving doping strategies and streamlining the time-consuming process of testing are highly desirable. Some suggest the use of metabolomics as an answer, but there are many limitations still to be addressed before this could become an efficient option [30]. Another possible option would be to test for biomarkers of drug doping, alleviating the need for the time-consuming process of testing for each illicit substance [31-33]. This would first require identification of such biomarkers. The functional genomic response to doping agents could be examined in vitro to identify biomarkers that could then be used as indicators for exposure to a particular agent. In addition, the metabolic, gene expression, immunological, signal transduction etc. response to doping substances could also be assessed in vitro to gain further detailed insight into the specific cellular impacts of doping agents.

Further sophisticated methods of doping by manipulating the inherited genome of an individual have become possible through advancements in gene therapy. Although not yet commonplace, research in the field of gene therapy is constantly improving [34-37] and with every advancement in genetic methods intended for hereditary disease therapies, comes further opportunities for exploiting the technology for doping strategies [38-42]. Therefore, developing methodologies to combat this is necessary [43-45]. Identifying probable targets for gene doping would be the first port of call in combating gene doping [46] followed by studying the gene expression profiles of equine skeletal muscle cells in response to various doping strategies. 'Normal' expression profiles in the published literature could be utilized for additional comparisons; such as MSTN which has been extensively researched, with gene expression data available for various exercise conditions [47] and is a prominent feature in the in vitro cell culture system discussed in this article. An in vitro equine muscle system would provide an excellent model for optimisation and analysis of these gene doping methods, provide a system to study the gene expression profiles resulting from these doping strategies [48] and could ultimately aid the development of suitable gene doping detection methods.

Furthermore, all of the aforementioned applications could be adapted for and applied to human skeletal muscle, to improve understanding of human muscle phenotypes and enable improvement of drug doping testing, supplement research and gene doping in human skeletal muscle.

Therefore, here we describe the establishment of novel equine skeletal muscle cell lines that may be used to investigate functional phenotypic variation resulting from genetic variation at the economically important myostatin (MSTM) locus. Horses with different MSTN genotypes, assigned as CC/II, CT/IN and TT/NN for the combined SNP g.66493737C>T/SINE insertion 227 bp polymorphisms [49] have variable metabolic and functional phenotypes $[47,49-56]$ that impact suitability to perform as a sprinter, middledistance or long distance ('endurance') racehorse. One of the principle phenotypic differences among the genotypes is a marked variation in skeletal muscle fibre type proportion and lower MSTN gene expression 
in the (CC/II) genotype $[55,57,58]$. We also previously reported that $\mathrm{CoQ}_{10}$, measured indirectly via electron transport chain complex I+III activity, in skeletal muscle of 'endurance' (TT/NN) genotype horses was significantly lower than that of the 'sprint' (CC/II) genotype, but observed in an 'add-back' experiment that addition of exogenous $\mathrm{CoQ}_{10}$ to ex vivo skeletal muscle samples from 'endurance' (TT/NN) genotype horses improved mitochondrial performance in that tissue [55]. This finding was mirrored in an in vivo supplementation trial in which oral dietary $\mathrm{CoQ}_{10}$ supplementation of Thoroughbred horses increased complex I+III activity $65 \%$ after a 9 -week supplementation period [59].

Here, we describe the creation of equine skeletal muscle cell lines with the three distinct genotypes. Using these cell lines, we characterise the in vitro metabolic phenotypes of the MSTN genotype cell lines to assess the feasibility and accuracy of immortalised cell lines for ongoing experiments and establish an efficient in vitro module for equine skeletal muscle. An in vitro cell line of this kind, particularly with its comparative genetic attribute, will enable a wide range of analyses in skeletal muscle research which could have considerable impact on the field of equine skeletal muscle research and provide economic benefit in this multi-billion-euro international industry. This cell model could also act as a progenitor to a similar human skeletal muscle approach which would be valuable to the human skeletal muscle research field.

To our knowledge this is the first description of establishing normal / wild-type cell lines that are differentiated on the basis of genotype. Several cell lines have been established from mouse specimens where genes have been knocked-out $[60,61]$, rather than developed with 'naturally occurring' polymorphic genotypic differences. Therefore, using this system for in vitro comparative genetic analysis is a unique approach that will allow for improved understanding of the functional effects of MSTN genetic variation that is not feasible in vivo.

\section{Methods}

\section{Materials}

Plasticware and other single-use consumables were obtained from Cruinn Ltd. unless stated otherwise. Cell culture media, fetal bovine serum (FBS), horse serum, phosphate buffered saline (PBS), TrypLE express dissociation agent, penicillin/streptomycin, puromycin, ProLong antifade gold mounting medium and anti-mouse alexaflour secondary antibody were from Biosciences $L t d$. Polybrene transfection reagent was from Merck Millipore. Lentiviral vector for immortalization and GFP control vector were from ABM (Germany). Slides and coverslips for immunofluorescence were from Fisher Scientific and VWR, respectively. Anti-desmin antibody (Cat\# 550626) was from BD Biosciences, anti-sarcomeric myosin antibody (Cat\# MAB4470) was from R\&D systems and Hoescht 33342 stain was from Life Technologies. All other chemicals/reagents were from Sigma-Aldrich, unless stated otherwise.

\section{C2C12 and 3T3-L1 cell culture}


C2C12(ATCC $\AA$ CRL-1772) cells, an immortal mouse derived adherent muscle myoblast cell line $[8,62]$ and 3T3-L1 (ATCC® CL-173) cells, an adherent pre-adipocyte fibroblast cell line $[63,64]$ were used as myogenic and non-myogenic controls, respectively, for immunostaining. Both cell lines were maintained in Dulbecco's Modified Eagle's Medium (DMEM) GlutaMAX cell culture medium (Gibco) (high glucose, with sodium pyruvate) supplemented with $10 \%$ (v/v) FBS (Invitrogen) and penicillin-streptomycin (50 $\mathrm{U} / \mathrm{ml}$ and $50 \mu \mathrm{g} / \mathrm{ml}$ ) (Gibco). Cells were grown at $37^{\circ} \mathrm{C}$ in a humidified environment with $5 \% \mathrm{CO}_{2}$. Cells were passaged at least twice weekly depending on their levels of confluency using TrypLE express (Gibco) dissociation reagent. C2C12 myoblast cells differentiated into myotubes upon confluency and differentiation was further encouraged by the reduction of serum concentration (to $2 \%$ horse serum) in the media. C2C12and 3T3-L1 cells were routinely tested for mycoplasma infections as per the method described by Young et al. [65].

\section{Animals and sample collection}

Skeletal muscle tissue samples were acquired with permission from an Irish abattoir. The samples used in the study were extracted immediately post-mortem from three horses which were euthanised for nonresearch purposes, therefore Health Products Regulatory Authority (HPRA) approval was not required. Veterinary records described no previous muscle related veterinary conditions in the horses sampled. Samples were taken from the gluteus medius skeletal muscle by scalpel dissection at a depth of approximately 4-8 cm. All three horses were Thoroughbreds, aged 14 [male], 10 [female] and 25 [male] years of age and their MSTN genotypes were CC/II, CT/IN and TT/NN respectively (SNP g.66493737C>T/SINE insertion 227 bp).

\section{MSTN genotyping}

DNA was extracted from hair samples and genotyped for the MSTNSNP g.66493737C>T [66] and the MSTNSINE insertion 227 bp polymorphism [54]. Primary and immortalised cell samples were similarly genotyped at various stages in the immortalisation process to confirm cross-contamination of cell lines had not occurred.

\section{Equine skeletal muscle myoblast isolation and culture}

Skeletal muscle tissue samples were placed directly into ice-cold supplemented cell culture media (DMEM GlutaMax, high glucose, with sodium pyruvate (Gibco) supplemented with 20\% FBS (Invitrogen), 10\% horse serum (HS) (HyClone) and penicillin-streptomycin (50 U/ml and $50 \mu \mathrm{g} / \mathrm{ml}$ ) (Gibco)) immediately post-extraction. Samples were transported on ice and stored at $4^{\circ} \mathrm{C}$ for approximately 16 hours prior to primary myoblast cell isolation.

To isolate myoblast cells, the muscle sample (approximately $1 \mathrm{~g}$ ) was washed with supplemented DMEM in a petri dish, any tendon, fat, vessels or connective tissue was carefully removed, and the tissue sample was sliced into very small fragments. The tissue fragments were transferred to a $50 \mathrm{ml}$ falcon tube and allowed to settle to the bottom at which point the supernatant was aspirated and discarded. The muscle 
fragments were resuspended in a $0.1 \%$ pronase solution in media and incubated at $37^{\circ} \mathrm{C}$ for 60 minutes with intermittent agitation every 15 minutes. After 1 hour, an equal volume of media was added to the tube to stop the reaction. The muscle fragments were further dissociated using vigorous trituration. The sample was repeatedly pipetted 10 times with a $25 \mathrm{ml}$ pipette, followed by 10 goes with a $10 \mathrm{ml}$ pipette. The sample was subsequently centrifuged at $400 \mathrm{~g}$ for 3 minutes to pellet the debris. The supernatant (containing the extracted cells) was poured through a $40 \mu \mathrm{m}$ cell strainer, which was then washed with fresh media, followed by centrifugation at $1,000 \mathrm{~g}$ for 10 minutes to pellet the cells. The cell pellet was resuspended in a small volume of media and seeded in a gelatin (2\%)-coated T25 flask in a 'pre-plating' step for 1 hour, to encourage removal of fibroblasts. After 1 hour the cells in suspension were removed and re-seeded in gelatin (2\%)-coated culture dishes as appropriating depending on cell volume. Cell cultures were left undisturbed at $37^{\circ} \mathrm{C}$ for 3 days. After 3 days the media was changed very gently, and the cells were continued to be monitored daily. First passage of cells usually took place between 7-10 days after isolation. At first passage cells were pre-plated as previous for 20 minutes before being reseeded into a fresh gelatin (2\%)-coated flask. Once a substantial population of cells had been obtained at passage 3-4 cell stocks were frozen and remaining cells were plated for immortalisation or immunostaining.

\section{Conditional immortalisation of equine myoblasts}

This immortalization protocol was adapted from a variety of publications $[17,67-70]$ to suit the parameters of this project and the optimal conditions for these cells.

Isolated primary myoblasts were seeded at $5 \times 10^{4}$ cells per well of a 6-well plate and cultured for 24-48 hours until at approximately $70 \%$ confluency. At this point the media was removed and replaced with a 1 $\mathrm{ml}$ mixture of complete media supplemented with polybrene at a concentration of $8 \mu \mathrm{l} / \mathrm{ml}$. The optimised multiplicity of infection (MOI) volume for the temperature-sensitive simian vacuolating virus 40 large $T$ antigen (SV40TtsA58 lentivirus) vector (MOI5 for $5 \times 10^{4}$ cells; $250 \mu \mathrm{l}$ of $1 \times 10^{6} \mathrm{lU} / \mathrm{ml}$ )) was added to each treatment well. The same amount of GFP control vector was added to a separate set of wells and at least one well was left untransduced as 'positive' and 'negative' controls, respectively. Cells were incubated at $33^{\circ} \mathrm{C}$ (temperature sensitive vector allows immortal growth at $33^{\circ} \mathrm{C}$ ) for 24 hours before the viral supernatant was removed and replaced with fresh media. Cells were incubated for a further 24 hours at $33^{\circ} \mathrm{C}$ at which point they were treated with $2 \mu \mathrm{g} / \mathrm{ml}$ of the selection antibiotic puromycin. Cells were cultured at $33^{\circ} \mathrm{C}$, passaging as necessary, for 7-14 days, at which point successful immortalization of transfected cells could be concluded based on efficient proliferation in the presence of puromycin, compared to puromycin induced death of untransfected control cells. Positive cell colonies that had survived the antibiotic selection were selected from the cell population using cloning rings and expanded by seeding and culturing in 24-well plate wells and then further in $\mathrm{T} 25 \mathrm{~cm}^{2}$ flasks. All clones were immunostained and imaged as per the methods described later in this manuscript (additional file 2). The cell clone chosen for each genotype was expanded further and stocks were frozen down and stored in liquid nitrogen vapour for future use. Immortalised cells were capable of growing in culture for numerous 
passages at $33^{\circ} \mathrm{C}$. Incubating the cells at $37^{\circ} \mathrm{C}$ resulted in the cells becoming 'primary-like' and capable of terminal differentiation.

GFP control cell samples were visualised under bright field and fluorescence microscope to assess transfection efficiency in these cells (additional file 1, supplemental figure 1A). Immunoblotting and PCR (as per methods in additional file 4) were also used to confirm the presence of SV40T in the immortalised cell samples (additional file 1, supplemental figure 1B and 1C).

\section{Immunostaining and confocal imaging}

Cells (primary, immortalised, 'primary-like' and differentiated) were immunostained and imaged by confocal microscopy as per the methods described herewith. Cells were seeded at $2 \times 10^{4}$ cells per well of a 24-well plate on inserted $12 \mathrm{~mm}$ circular glass coverslips and were incubated at $33^{\circ} \mathrm{C}$ (immortalised) or $37^{\circ} \mathrm{C}$ (primary, 'primary-like', differentiated) for 2 days until approximately $90 \%$ confluent. At this point media on the cells destined for differentiation was changed to the reduced serum ( $2 \% \mathrm{HS})$ media and the cells were cultured for a further 5-10 days until the cells terminally differentiated into myotubes.

To fix the cell cultures, media was removed, cells were washed and $200 \mu \mathrm{l}$ of ice-cold acetone:methanol (1:1) fixative solution was added to each well and the cells were fixed for 10 minutes at room temperature. The fixative solution was removed carefully, and the well was washed three times with trisbuffered saline (150 mM NaCl, $20 \mathrm{mM}$ Tris-HCl, pH 7.6) (TBS). To block nonspecific antibody binding, 500 $\mu$ l of blocking solution (TBS supplemented with $5 \%$ BSA) was added to each well and the plate was incubated at $4^{\circ} \mathrm{C}$ overnight. Following overnight incubation at $4^{\circ} \mathrm{C}$ the plates were returned to room temperature and washed three times with TBS prior to antibody staining. Primary antibodies were diluted in blocking solution at 1:100 and 1:250 dilution of desmin (BD) and sarcomeric myosin (R\&D/Bio-techne), respectively and $150 \mu \mathrm{l}$ of appropriate antibody solution was added to the appropriate well. Cells were incubated with primary antibodies at room temperature with gentle swirling for 3 hours. Subsequently, wells were washed with TBS three times and then incubated with goat anti-mouse AlexaFluor 488 secondary antibody (thermo-fisher) at 1:1000 dilution in blocking solution for 1 hour at room temperature. The secondary antibody solution was removed, and the cells were washed with TBS as previous. For nuclear visualization $100 \mathrm{ul}$ of Hoescht solution ( $1 \mathrm{ug} / \mathrm{ml}$ diluted in TBS) was incubated with the cells for 30 minutes at room temperature. Cells were washed once again prior to the coverslip being mounted on to a glass slide using 1 drop of ProLong Antifade mounting medium. Slides were kept in the dark for 24 hours at room temperature, then sealed and imaged using confocal microscopy. A Leica SP8 scanning confocal microscope with a 488 laser (max excitation 490, max emission 525) at 20X zoom was used to image slides.

\section{Enzyme Assays}

Citrate synthase enzyme activity was used as a marker of mitochondrial abundance in the skeletal muscle cells. $\mathrm{CoQ}_{10}$ content was measured indirectly by spectrophotometric combined complex I+III assay. Enzyme activity assays were performed at $30^{\circ} \mathrm{C}$ on a Libra S12 spectrophotometer (Biochrom Ltd., 
Cambridge, UK) with absorbance changes measured using an attached chart recorder. The activity of each enzyme was measured in triplicate on the same homogenate for each sample.

\section{Preparation of cell homogenates}

Equine skeletal muscle myoblasts were grown and differentiated as described earlier in methods section. Equal numbers of cells were pelleted and washed with PBS before being resuspended in $100 \mu$ hypotonic potassium phosphate buffer $\left(25 \mathrm{mM} \mathrm{K}_{2} \mathrm{PO}_{4}, 5 \mathrm{mM} \mathrm{MgCl}_{2}\right)$. Each sample was subjected to three freeze thaw cycles in liquid nitrogen to disrupt biological membranes. An aliquot of each sample was used to perform protein determination using the bicinchoninic acid assay as described by Smith et al. [71] and the rest was used for enzyme activity assays.

\section{Citrate synthase activity assay}

Citrate synthase enzyme activity (a measure of mitochondrial abundance) was measured spectrophotometrically by a coloured coupled reaction, using a method adapted from Srere [72]. The activity of citrate synthase was determined by monitoring the rate of production of thionitrobenzoic acid at a wavelength of $412 \mathrm{~nm}$. Skeletal muscle cell homogenate was incubated in a $1 \mathrm{ml}$ cuvette with tris buffer (0.2 M, pH 8.1) with reaction components added: 5,5'-dithiobis-(2-nitrobenzoic acid) (0.1 mM), acetyl coenzyme A $(0.3 \mathrm{mM})$ and Triton X (0.1\%). A blank rate was measured for 2 mins before oxaloacetate $(0.5 \mathrm{mM})$ was added to initiate the reaction and an increase in absorbance was monitored for 3 mins. Specific enzyme activity was expressed as $\mathrm{pmol} / \mathrm{min} / \mathrm{mg}$ of muscle protein using the molar extinction coefficient $13,600 \mathrm{~L} / \mathrm{mol} / \mathrm{cm}$ for citrate synthase at $412 \mathrm{~nm}$.

\section{NADH cytochrome c oxidoreductase (Complex I+III) activity assay}

The activity of $\mathrm{NADH}$ cytochrome $c$ oxidoreductase (Complex I+III, an indirect measure of $\mathrm{CoQ}_{10}$ ) was determined by monitoring the reduction of cytochrome $\mathrm{c}$ at $550 \mathrm{~nm}$, as per the method described by Powers et al. [73]. Cell homogenates were incubated in distilled $\mathrm{H}_{2} \mathrm{O}$ in a $1 \mathrm{ml}$ cuvette to allow osmotic shock to occur. After 2 mins incubation, the reaction components were added: potassium phosphate $\mathrm{pH}$ $7.5(50 \mathrm{mM})$, oxidised cytochrome c $(50 \mu \mathrm{M}), \mathrm{KCN}(0.3 \mathrm{mM})$, and fatty-acid free BSA $(1 \mathrm{mg} / \mathrm{ml})$; a blank rate was measured for 2 mins. $\mathrm{NADH}(0.2 \mathrm{mM})$ was then added to initiate the reaction and an increase in absorbance was monitored for 3 mins. Following this, rotenone $(10 \mu \mathrm{M})$ was added and the rate was monitored for a further 2 mins. Complex I+III combined specific activity was taken as the rotenonesensitive activity determined by subtracting the rotenone-resistant activity from the total activity. Specific enzyme activity for complex I+III was expressed as $\mathrm{pmol} / \mathrm{min} / \mathrm{mg}$ of muscle protein using the molar extinction coefficient $18,500 \mathrm{~L} / \mathrm{mol} / \mathrm{cm}$ for reduced cytochrome $c$ at $550 \mathrm{~nm}$. Complex I+III activity was subsequently expressed as a ratio to citrate synthase activity to account for the mitochondrial enrichment of the cells.

\section{Gene expression}


Total RNA was isolated from skeletal muscle cell samples using Qiazol reagent (Qiagen) and was isolated and purified using RNeasy Plus Universal kit (Qiagen) as per the manufacturer's instructions. Equal amounts of RNA were reverse transcribed into cDNA using the High-Capacity cDNA Reverse Transcription Kit (Applied Biosystems) as per manufacturer's instructions. Reverse transcription was performed by heating the reaction mix at $25^{\circ} \mathrm{C}$ for 10 minutes followed by $37^{\circ} \mathrm{C}$ for 120 minutes and $85^{\circ} \mathrm{C}$ for 5 minutes. The resulting cDNA was then diluted with nuclease free water and used for real-time qPCR. Careful attention was paid to avoid PCR contamination and no false-positives were observed in negative controls. Biosystems 7500 Fast Real-Time PCR System and SYBR green reagents were used to measure mRNA in equine skeletal muscle tissue. Specific primers and qPCR conditions were as previously described for MSTN; Rooney et al. [54] and for HPRT, MYH7, MYH2, MYH1; Rooney et al. [55]. All reactions were run in at least duplicate. SDS 1.9.1 software (Applied Biosystems) was used to analyse the amplification curves and these curves were used to determine the relative mRNA expression of each gene. The expression of each gene was normalised to the expression of HPRT using the $\triangle \triangle \mathrm{Ct}$ method. Myosin heavy chain (MHC) isoform gene expression ( $M Y H 7, M Y H 2$ and $M Y H 1)$ was subsequently expressed as a percentage of total MHC gene expression.

\section{Cellular respiration using Seahorse XFp Analyser}

Cellular oxygen consumption rates (OCR) were determined by Seahorse XFp Extracellular Flux analyser (Agilent Technologies) with 10,000 cells per well. Appropriate volumes of the mitochondrial inhibitors/uncouplers were added to the Seahorse XFp cartridge prior to experimentation and were introduced automatically by the machine in a sequential manner during the experiment. The following final concentrations were used; oligomycin $1 \mu \mathrm{M}$, FCCP $1 \mu \mathrm{M}$ and antimycin $\mathrm{A}(\mathrm{AA}) /$ rotenone $0.5 \mu \mathrm{M}$.

\section{Fluorescence lifetime imaging microscopy (FLIM) of $\mathrm{NAD}(\mathrm{P}) \mathrm{H}$}

Immortalised equine skeletal muscle myoblasts were grown as per the usual methods in $35 \mathrm{~mm}$ petri dishes and at confluence were used for fluorescence lifetime imaging microscopy (FLIM) of NAD (P)H. FLIM was performed on a custom multiphoton system. A titanium:sapphire laser (Chameleon, Coherent) was used for multiphoton excitation on an upright (Olympus BX61WI) laser scanning microscope coupled with a water-immersion $25 x$ objective (Olympus, 1.05NA). Two-photon excitation of NAD $(P) H$ was performed using $760 \mathrm{~nm}$ as excitation wavelength. A 455/90 nm bandpass filter was used to isolate $\mathrm{NAD}(\mathrm{P}) \mathrm{H}$ fluorescence signal. Images (512x512 pixel) were acquired with a pixel dwell time of $3.81 \mu \mathrm{s}$ and 30-second collection time. A PicoHarp 300 TCSPC system operating in the time-tagged mode coupled with a PMA hybrid detector (PicoQuanT GmbH, Germany) was used for fluorescence decay measurements yielding 256 time bins per pixel. The samples were placed on an incubating microscope stage at $37^{\circ} \mathrm{C}$ and for each individual sample, at least three separate images from different areas of the dish were acquired.

The fluorescence images and decay curves for $\mathrm{NAD}(\mathrm{P}) \mathrm{H}$ were obtained and the overall decay curve was generated by the contribution of all pixels and was fitted with a double exponential decay curve, for GFP 
and $\mathrm{NAD}(\mathrm{P}) \mathrm{H}$, respectively (Eq. 1)

$$
I(t)=\alpha_{1} e^{-\frac{t}{\tau_{1}}}+\alpha_{2} e^{-\frac{t}{\tau_{2}}}+C
$$

1

$I(t)$ corresponds to the fluorescence intensity measured at time $t$ after laser excitation; $a_{1}$ and $a_{2}$ represents the fraction of the overall signal comprise of a short - free NADH and long lifetime - protein bound NADH component, respectively. $\tau_{1}$ and $\tau_{2}$ are the short and long lifetime components, respectively; $c$ corresponds to background light.

$X^{2}$ value is calculated to evaluate the goodness of multiexponential fit to the raw fluorescence decay data. In this study all the values with $\mathrm{X}^{2}<1.3$ were considered good fits.

The average lifetime $\left(\tau_{\mathrm{avg}}\right)$ of $\mathrm{NAD}(\mathrm{P}) \mathrm{H}$ for each pixel is calculated by a weighted average of both free and bound lifetime contributions (Eq. 2).

$$
\tau_{a v g}=\frac{\left(\alpha_{1} \times \tau_{1}\right)+\left(\alpha_{2} \times \tau_{2}\right)}{\left(\alpha_{1}+\alpha_{2}\right)}
$$

The optical redox ratio (ORR) was calculated using equation 2:

$$
O R R=\frac{F A D^{+}}{N A D(P) H}
$$

With $\mathrm{NAD}(\mathrm{P}) \mathrm{H}$ being the total fluorescence intensity acquired at the $455-490 \mathrm{~nm}$ and $F A D^{+}$the total fluorescence intensity acquired at $502-547 \mathrm{~nm}$. The intensity of both images at different channels was obtained by conserving the same region of interest (ROI) in the Symphotime® software.

\section{Statistical analysis}

Statistical analyses were performed using Prism (GraphPad Software, California, USA). Mean values were compared using a one-way or two-way ANOVA as appropriate, with a Bonferroni multiple comparison post-test, $p$-values where shown indicate significance $\left(*=p \leq 0.05\right.$, ${ }^{*}=p \leq 0.01$, $\left.* \star *=p \leq 0.001\right)$, with results expressed as mean \pm SEM unless otherwise indicated.

\section{Results And Discussion}

\section{Isolation and conditional immortalisation of equine skeletal muscle myoblasts}

Obtaining fresh equine skeletal muscle biopsy specimens regularly for functional assays poses many limitations in sample collection which we sought to circumvent by establishing a series of conditionally immortalised equine skeletal muscle cell lines. Several successful immortalisations of skeletal muscle 
cells from other species such as human, mouse, pig and other mammals [8, 70,74-79] exist and successful immortalisation of equine skeletal muscle cells has previously been reported [17]. Here, the aim was to establish equine skeletal muscle cell lines exhibiting variable functional phenotypes associated with natural genetic variation in the population of interest, that would facilitate assessment of functional assays relevant to the variable phenotypes.

Therefore, we established three working immortal equine skeletal muscle cell lines that are distinguishable on the basis of genotype for the most economically important locus in the horse racing and breeding industry. Primary equine skeletal muscle myoblasts were isolated from three MSTN genotype Thoroughbred horses (CC/II, CT/IN and TT/NN for SNP g.66493737C>T/SINE insertion 227 bp polymorphism) and conditionally immortalised by transfecting with the SV40TtsA58 lentivirus vector. The SV40TtsA58 vector contains a temperature sensitive region (tsA58 gene, located between 3138$5264 \mathrm{bp}$ ), with an alanine-to-valine mutation at amino acid 438 , active only at $33^{\circ} \mathrm{C}$. When cells are cultured at this temperature, they grow immortally. When cultured at $37^{\circ} \mathrm{C}$ they return to a 'primary-like' condition and are capable of terminal differentiation [80-82]. The general transfection efficiency of these cells was assessed using a green fluorescent protein (GFP) control vector and successful transfection specifically with the SV40TtsA58 vector was confirmed by detection of SV40T DNA and protein in cell samples (additional file 1).

After successful transfection, antibiotic and clonal selection was employed to isolate several cell clones for each genotype. We identified, selected, and expanded a single clone for each genotype. Through expansion of these cell lines, we confirmed that the cells could proliferate prosperously, and confirmed via immunostaining that these cell lines are of myogenic phenotype with positive expression of desmin (a muscle-specific, type III intermediate filament) and confirmed that the cells could be terminally differentiated into multinucleated myotubes, using immunostaining for myogenin (a muscle-specific transcription factor involved in the coordination of skeletal muscle development) (figure 1). Immunostaining was performed on the cells at each stage; primary myoblasts, conditionally immortalised myoblasts, immortalised myoblasts reverted to 'primary-like' conditions and immortalised 'primary-like' terminally differentiated myotubes. 3T3-L1 and C2C12 cells were imaged as a negative-and positive-myogenic control, respectively (additional file 2 ).

Fibre type proportions, MSTN gene expression and mitochondrial abundance of immortal cell lines are comparable to ex vivo skeletal muscle

Having established that the immortalised equine skeletal muscle cell lines were capable of terminal differentiation when returned to 'primary-like' conditions, we characterised the phenotypic and metabolic status of each genotype, in order to validate and compare with characteristics previously obtained for $e x$ vivo skeletal muscle tissue of the same genotypes $[55,57]$.

Previously using muscle biopsy samples [55], we observed a significant difference in muscle fibre type proportions among the three genotypes [55]. The expression of three genes; $M Y H 7, M Y H 2$ and $M Y H 1$, which are primarily expressed in Type I, Type IIA and Type IIX muscle fibres respectively [80, 83], were 
quantified (Figure 2A). In agreement with ex vivo observations, the TT/NN cell line had higher $M Y H 7$ gene expression and indicating it contained a higher proportion of type I fibres compared to the $\mathrm{CC} / \mathrm{II}$ ( $p \leq 0.001)$ and CT/IN ( $p \leq 0.001)$ cell lines. The opposite profile was observed for expression of $M Y H 1$, with the CC/II cell line having a higher proportion of type IIX fibres compared to the CT/IN $(p \leq 0.001)$ and $\mathrm{TT} / \mathrm{NN}(\mathrm{p} \leq 0.001)$ cell lines. The CT/II cell line had significantly higher expression of $M Y H 2$, therefore more type IIA fibres than the CC/II $(p \leq 0.001)$ and TT/NN $(p \leq 0.001)$ cell lines. Fibre type proportions, expressed as a percentage of total, for each fibre type are displayed in figure $2 \mathrm{~A}$ and shown in Table 1. These results are consistent with previous observations from ex vivo samples of skeletal muscle tissue of Thoroughbreds and their respective genotypes $[55,58]$.

Table 1

Fibre type proportions in immortalised cell lines. Data expressed as $\%$ of total $( \pm$ SEM) $n=3$ per genotype.

\begin{tabular}{|llll|}
\hline & I & IIA & IIX \\
\hline $\mathrm{CC} / \mathrm{II}$ & $1.4( \pm 0.6)$ & $23.0( \pm 1.8)$ & $75.6( \pm 2.4)$ \\
$\mathrm{CT} / \mathrm{IN}$ & $4.7( \pm 0.2)$ & $45.8( \pm 2.3)$ & $49.5( \pm 2.5)$ \\
$\mathrm{TT} / \mathrm{NN}$ & $33.4( \pm 2.5)$ & $33.3( \pm 1.2)$ & $33.3( \pm 1.3)$ \\
\hline
\end{tabular}

A key feature of the CC/II genotype is the lower expression of MSTN mRNA in skeletal muscle with the consequent increase in muscle mass [84] and fast-twitch fibre type [54, 55, 57]. Here, consistent with previous ex vivo skeletal muscle sample analysis [54], MSTN gene expression was significantly higher in the TT/NN cell line compared to the CT/IN $(p \leq 0.001)$ and the CC/II $(p \leq 0.001)$ cell lines (Figure $2 B)$. As such, we next hypothesised that there would be a lower mitochondrial abundance in skeletal muscle with more fast twitch muscle fibres, than in skeletal muscle with more slow twitch fibres. Here, citrate synthase activity, an established marker of mitochondrial abundance [72] was significantly higher in the TT/NN cell line compared to the CT/IN $(p \leq 0.01)$ and the $C C / I I(p \leq 0.05)$ cell lines (Figure $2 C)$. This pattern directly reflects previous findings in skeletal muscle homogenates from TT/NN horses that had significantly greater mitochondrial abundance (determined by citrate synthase activity and mitochondrial DNA content) when compared to $\mathrm{CC} / \mathrm{II}$ skeletal muscle homogenates [55].

\section{In vitro $\mathrm{CoQ}_{10}$ supplementation increases complex I+III activity}

Previously we found that ex vivo skeletal muscle homogenates from TT/NN horses had a lower combined mitochondrial complex I+III activity, indicative of a lower endogenous $\mathrm{CoQ}_{10}$ level, when compared to CC/II skeletal muscle homogenates [55]. This lower mitochondrial complex I+III activity level in the TT/NN homogenates could be restored in vitro by the addition of exogenous $\mathrm{CoQ}_{10}$ to ex vivo skeletal muscle homogenates. In a separate study, exogenous $\mathrm{CoQ}_{10}$ supplementation in vivo to a cohort 
of horses showed that oral $\mathrm{CoQ}_{10}$ supplementation increased complex I+III activity in ex vivo skeletal muscle of Thoroughbreds [59].

Here, to test the hypothesis that $\mathrm{CoQ}_{10}$ supplementation in vitro would increase cellular complex I+III activity (indicating increased $\mathrm{CoQ}_{10}$ ) in skeletal muscle, we added, exogenous $\mathrm{CoQ}_{10}$ to the three conditionally immortalised cell lines in vitro at a concentration of $5 \mu \mathrm{M}$ for 24 hours. Cells were then lysed and $\mathrm{CoQ}_{10}$ content was measured indirectly using the combined mitochondrial complex I+III enzyme activity. We observed that in the untreated cells complex I+III activity was significantly higher in the CC/II cells as compared to the CT/IN ( $p \leq 0.05)$ and TT/NN ( $\leq \leq 0.01)$ cells (Figure 2D), an observation consistent with previous ex vivo muscle homogenate data [55]. Furthermore, addition of exogenous $\mathrm{CoQ}_{10}(5 \mu \mathrm{M}$ for 24 hours) increased complex I+III enzyme activity significantly in all three genotype cell lines $(p \leq 0.05)$, a result that is also in agreement with previously published results [59].

\section{Cellular respiration and oxidative metabolism of conditionally immortalised skeletal muscle cell lines}

Having established that these novel immortal cell lines exhibit phenotypic and metabolic characteristics equivalent to ex vivo and in vivo tissue samples we have determined that the conditionally immortalised TT/NN, CT/IN and the CC/II cell lines authentically reflect the skeletal muscle phenotype of Thoroughbred horses with each genotype. Therefore, these three cell lines are a valid in vitro model of variable MSTN genotype skeletal muscle and may be used for further characterisation of horse skeletal muscle function.

Therefore, to compliment the mitochondrial complex activity assays, we performed a comparison of cellular oxygen consumption between the three cell lines. Differences in mitochondrial abundance and function are reflected in cellular oxygen consumption [85]. We measured basal cellular oxygen consumption using the Seahorse XFp extracellular flux analyser using three selective mitochondrial inhibitors to assess different aspects of mitochondrial function 1) rate of proton leak (oligomycin to inhibit ATP synthase) 2) maximal respiratory capacity (carbonyl cyanide-p-

trifluoromethoxyphenylhydrazone (FCCP) to uncouple the mitochondria) and 3) non-mitochondrial respiration rate (antimycin $\mathrm{A}$ /rotenone which inhibit complex III and I respectively, effectively inhibiting all mitochondrial respiration) $[85,86]$.

Comparison of the cell lines in both primary (Figure 3A/B) and immortalised (Figure 3C/D) conditions, showed no significant difference in basal, proton leak or non-mitochondrial oxygen consumption rates among the three genotypes. However, after the addition of the uncoupler FCCP, primary TT/NN cells reached a greater maximal respiration rate than the primary $\mathrm{CC} / \mathrm{Il}$ cells $(\mathrm{p} \leq 0.05)$. A similar profile was observed in the immortalised cell lines, with the TT/NN cell line also attaining a higher maximal oxygen consumption rate compared to the $\mathrm{CC} / \mathrm{II}(\mathrm{p} \leq 0.05)$ cell line. These oxygen consumption results likely reflect the greater mitochondrial abundance in TT/NN compared to $\mathrm{CC} / \mathrm{Il}$ cell lines. 
Finally, to further assess the oxidative status of the cells, we performed fluorescence lifetime imaging (FLIM) analysis, which is a non-invasive technique to measure $\mathrm{NAD}(\mathrm{P}) \mathrm{H}$ fluorescence lifetimes and respective fractions in cells (Figure $3 \mathrm{E}$ ). Values used to calculate the average fluorescence lifetime ( $\tau_{\text {avg }}$ ) of $\mathrm{NAD}(\mathrm{P}) \mathrm{H}$ are shown in supplementary table 1 (additional file 3 ). An increase of $\tau_{\text {avg }}$ values is indicative of a cellular metabolic preference for the oxidative phosphorylation pathway [87-89]. Our results (Figure 3F) showed that the TT/NN cell line was significantly more oxidative than the CC/II cell line $(p \leq 0.05)$, an observation consistent with the mitochondrial abundance and function results.

In addition to the $\mathrm{NAD}(\mathrm{P}) \mathrm{H}$ fluorescence lifetimes, the optical redox ratio (ORR) of the different cell lines was calculated. ORR is a ratio of the fluorescence intensity of $F A D^{+}$and $N A D(P) H$ which provides insight on the cell oxidative and metabolic state $[87,90,91]$. $F A D^{+}$is a fluorescence metabolic co-factor that during the Krebs cycle is reduced to FADH recovered by hydrogen transfer at the Complex II of the electron transport chain. $\mathrm{NAD}(\mathrm{P}) \mathrm{H}$ is formed during the Krebs cycle or earlier steps of glycolysis and oxidised to $\mathrm{NAD}(\mathrm{P})^{+}$at Complex I $[89,92,93]$.

Our results show a statistically significant increase in the ORR of $\mathrm{CC} / \mathrm{Il}$ cell line when compared with TT/NN cell line. However, no statistical significance was found when compared with CT/IN (Figure 3G). The increase in the ORR can be justified by a shift towards a decrease of the NAD $(P) H$ pool while maintaining or increasing $\mathrm{FAD}^{+}$availability. Our previous results (Figure $2 \mathrm{C}$ ) show an increase in citrate synthase activity in the TT/NN cell line which is likely reflective of a higher abundance of mitochondria and $\mathrm{NAD}(\mathrm{P}) \mathrm{H}$ molecules [72]. In addition, complex I+III activity is reduced in the TT/NN cell line (Figure 2D) which decreases the consumption of $\mathrm{NAD}(\mathrm{P}) \mathrm{H}$ by the electron transport chain. The conjugation of both results indicates an increase of $\mathrm{NAD}(\mathrm{P}) \mathrm{H}$ availably resulting in a reduction of the ORR (Figure $3 \mathrm{G}$ ), leading to the conclusion that the TT/NN cell line is more oxidative than the CC/II cell line as measured by FLIM analysis (Figure 3E/F/G).

\section{Maximal mitochondrial respiratory capacity of skeletal muscle cell lines was increased by CoQ 10 supplementation}

Since we previously demonstrated that oral supplementation with $\mathrm{CoQ}_{10}$ in vivo and exogenous $\mathrm{Co}_{10}$ during in vitro experiments improved mitochondrial complex I+III activity in ex vivo skeletal muscle samples from TT/NN horses, we tested whether supplementation of $\mathrm{CoQ}_{10}$ to the TT/NN cell line improved in vitro mitochondrial function. The addition of $\mathrm{CoQ}_{10}(5 \mu \mathrm{M}$ for 24 hours $)$ had no significant effect on any cell line for basal, proton leak or non-mitochondrial respiration rates (Figure 3C/D).

However, at maximal respiration capacity, the TT/NN cell lines, when treated with $\mathrm{CoQ}_{10}$, attained a higher maximal oxygen consumption rate than untreated cells $(p \leq 0.05)$. We therefore conclude that $\mathrm{Co}_{10}$ augmented the maximal mitochondrial electron transport chain capacity in the $T T / N N$ cells. $\mathrm{CoQ}_{10}$ has 
previously been proposed as a potential supplement to improve exercise capacity, aerobic power and recovery after exercise [94-98]. Here, we provide in vitro evidence indicating that $\mathrm{CoQ}_{10}$ supplementation improves the mitochondrial respiratory capacity of skeletal muscle cells.

\section{Conclusions}

We have established three conditionally immortalised skeletal muscle cell lines that represent an in vitro model of Thoroughbred horse skeletal muscle MSTN genotypes CC/II, CT/IN and TT/NN.

Characterisation of these cell lines in terms of MSTN gene expression, muscle fibre type and metabolic function, confirmed that they mirror ex vivo skeletal muscle tissue phenotypes from equivalent genotype horses (e.g. fast-twitch fibres, low mitochondrial abundance and low myostatin expression in $\mathrm{CC} / \mathrm{II}$ genotype). The establishment of these cell lines enabled evaluation of cellular oxygen consumption, previously not feasible due to the logistical challenges of obtaining ex vivo muscle specimens. In addition, we have demonstrated that addition of $\mathrm{CoQ}_{10}$ improves mitochondrial function in these cell lines, an observation consistent with previous in vivo studies and studies using ex vivo skeletal muscle samples. Importantly, we demonstrated that $\mathrm{CoQ}_{10}$ can increase the maximal mitochondrial respiration capacity in skeletal muscle cells, a finding that validates the hypothesis that $\mathrm{CoQ}_{10}$ can improve equine skeletal muscle energy metabolism.

We conclude that the validity of the conditionally immortalised MSTN genotype cell lines as being representatives of their original ex vivo skeletal muscle source has been established, and thus they are reliable models of Thoroughbred skeletal muscle with these genotypes. These cell lines thus not only provide a feasible means to assess genotypic differences on cellular phenotype and metabolism, but also a means to assess how supplementation can modulate these cellular processes. This model will be a valuable resource for future equine skeletal muscle research and may be applied to a range of investigations relevant to the Thoroughbred industry, especially in the area of gene doping and the detection of prohibited substances.

\section{Declarations}

\section{Ethics approval and consent to participate}

All samples were obtained post-mortem from animals euthanized for non-research purposes. Owners consent was given.

\section{Consent for publication}

Not applicable.

\section{Availability of data and materials}


The datasets generated and analysed during the study are available from the corresponding author on reasonable request.

\section{Competing interests}

EWH is a shareholder in and Chief Scientific Officer of Plusvital Ltd., an equine nutrition and genetic testing company. Plusvital Ltd. has been granted a licence for commercial use of the data that is contained within multiple granted patents and patent applications including (patent reference numbers): EP2352850, JP5667057, US8771943, AU2009290452, NZ591711, US9249470 and US2016215335. EWH is named on these patents.

\section{Funding}

This study has emanated from research conducted with financial support from Enterprise Ireland Innovation Partnership program grants (IP/2016/0503 awarded to RKP and IP/2019/0768 awarded to MFR), with Plusvital Ltd., as the Innovation Partner. Other than EWH, the funders played no role in the study design, data collection and analysis, decision to publish, or preparation of the manuscript. NN is supported by a Trinity College Dublin, Provost's PhD Award and the TCD FLIM core unit directed by MM is supported by a SFI Infrastructure Programme: Category D Opportunistic Funds Call (16/RI/3403) from Science Foundation Ireland (SFI).

\section{Author's contributions}

MFR conceived and designed the study, performed the experiments, analysed the data, and wrote the manuscript; NGBN performed, and MGM overseen the FLIM experiments; RKP supervised the project; EWH was involved in the coordination and execution of sample collection, provided insight into MSTN and assisted with the manuscript preparation. All authors read, edited, and approved the final submission.

\section{Acknowledgements}

The authors would like to thank Emerald Isle Foods Ltd. for their cooperation in obtaining post-mortem equine skeletal muscle samples. We would like to give special thanks to Dr. Michael Griffin for his assistance during the initial stages of the project, specifically, in the coordination and execution of skeletal muscle sample collection. We also thank Prof. Vincent Kelly for valuable comments and discussion during the study.

\section{References}


1. Jacoby, W. \& Pasten, I. Methods in enzymology: Cell culture Vol. 58 (Academic Press, New York, 1979).

2. Freshney, R. I. Culture of animal cells: A manual of basic technique and specialized applications (John Wiley \& Sons, 2015).

3. Polli, J. E. In vitro studies are sometimes better than conventional human pharmacokinetic in vivo studies in assessing bioequivalence of immediate-release solid oral dosage forms. AAPS J. 2008;10(2):289-99. 10.1208/s12248-008-9027-6

4. Moleiro, A., Conceição, G., Leite-Moreira, A. \& Rocha-Sousa, A. A critical analysis of the available in vitro and ex vivo methods to study retinal angiogenesis. J Ophthalmol. 2017;2017.

$10.1155 / 2017 / 3034953$

5. Scherer, W. F., Syverton, J. T. \& Gey, G. O. Studies on the propagation in vitro of poliomyelitis viruses: Iv. Viral multiplication in a stable strain of human malignant epithelial cells (strain hela) derived from an epidermoid carcinoma of the cervix. J Exp Med, 97 (5), 695-710 (1953).

6. Soule, H., Vazquez, J., Long, A., Albert, S. \& Brennan, M. A human cell line from a pleural effusion derived from a breast carcinoma. J Natl Cancer I, 51 (5), 1409-16 (1973).

7. Biedler, J. L., Helson, L. \& Spengler, B. A. Morphology and growth, tumorigenicity, and cytogenetics of human neuroblastoma cells in continuous culture. Cancer Res, 33 (11), 2643-52 (1973).

8. Yaffe, D. \& Saxel, O. Serial passaging and differentiation of myogenic cells isolated from dystrophic mouse muscle., 270 (5639), 725-7 (1977).

9. Graham, F. L., Smiley, J., Russell, W. \& Nairn, R. Characteristics of a human cell line transformed by DNA from human adenovirus type 5. J Gen Virol, 36 (1), 59-72 (1977).

10. Hayflick, L. \& Moorhead, P. S. The serial cultivation of human diploid cell strains. Exp Cell Res, 25 (3), 585-621 (1961).

11. Hayflick, L. The limited in vitro lifetime of human diploid cell strains. Exp Cell Res, 37 (3), 614-36 (1965).

12. González-Gualda, E., Baker, A. G., Fruk, L. \& Muñoz-Espín, D. A guide to assessing cellular senescence in vitro and in vivo. FEBS J, 288 (1), 56-80 (2021).

13. Gollahon, L. S. et al. Telomerase activity during spontaneous immortalization of li-fraumeni syndrome skin fibroblasts., 17 (6), 709-17 (1998).

14. Geens, M. M. \& Niewold, T. A. Optimizing culture conditions of a porcine epithelial cell line ipec-j2 through a histological and physiological characterization., 63 (4), 415-23 (2011).

15. Diebold, Y. et al. Characterization of a spontaneously immortalized cell line (ioba-nhc) from normal human conjunctiva. Invest Ophth Vis Sci, 44 (10), 4263-74 (2003).

16. Baquero-Perez, B., Kuchipudi, S. V., Nelli, R. K. \& Chang, K-C. A simplified but robust method for the isolation of avian and mammalian muscle satellite cells. BMC Cell Biol, 13 (1), 16 (2012).

17. Naylor, R. J. \& Piercy, R. J. Development of a clonal equine myoblast cell line capable of terminal differentiation into mature myotubes in vitro. Am J Vet Res, 76 (7), 608-14 (2015). 
18. Fernandez-Fuente, M. et al. Assessment of the transformation of equine skin-derived fibroblasts to multinucleated skeletal myotubes following lentiviral-induced expression of equine myogenic differentiation 1. Am J Vet Res, 69 (12), 1637-45 (2008).

19. Amilon, K. R. et al. Generation of functional myocytes from equine induced pluripotent stem cells. Cell Reprogram, 20 (5), 275-81 (2018).

20. Geor, R. J. The role of nutritional supplements and feeding strategies in equine athletic performance. Comp Exerc Physiol, 3 (3), 109-19 (2006).

21. Agar, C., Gemmill, R., Hollands, T. \& Freeman, S. The use of nutritional supplements in dressage and eventing horses. Vet Rec, 3 (1), e000154 (2016).

22. Gemmill, R., Agar, C., Freeman, S. \& Hollands, T. Factors affecting owners' choice of nutritional supplements for use in dressage and eventing horses. Vet Rec, 3 (1), e000155 (2016).

23. Murray, J., Hanna, E. \& Hastie, P. Equine dietary supplements: An insight into their use and perceptions in the irish equine industry. Irish Vet J, 71 (1), 1-6 (2018).

24. Roberts, J. L. \& Murray, J-A. Equine nutrition in the united states: A review of perceptions and practices of horse owners and veterinarians. J Equine Vet Sci, 34 (7), 854-9 (2014).

25. Roberts, J. L. \& Murray, J-A. Survey of equine nutrition: Perceptions and practices of veterinarians in georgia, USA. J Equine Vet Sci, 33 (6), 454-9 (2013).

26. Dodge, T. Consumers' perceptions of the dietary supplement health and education act: Implications and recommendations. Drug Test Anal, 8 (3-4), 407-9 (2016).

27. Starr, R. R. Too little, too late: Ineffective regulation of dietary supplements in the united states. $A m \mathrm{~J}$ Public Health, 105 (3), 478-85 (2015).

28. Dwyer, J. T., Coates, P. M. \& Smith, M. J. Dietary supplements: Regulatory challenges and research resources. Nutrients, 10 (1), 41 (2018).

29. Wong, J. K. \& Wan, T. S. Doping control analyses in horseracing: A clinician's guide. Vet J, 200 (1), 816 (2014).

30. Botrè, F., Georgakopoulos, C. \& Elrayess, M. A. Metabolomics and doping analysis: Promises and pitfalls.Bioanalysis; 2020. 10.4155/bio-2020-0137.

31. Cheung, H. W. et al. Label-free proteomics for discovering biomarker candidates of rad140 administration to castrated horses. Drug Test Anal, 13 (5), 1034-47 (2021).

32. Aikin, R., Baume, N., Equey, T. \& Rabin, O. Biomarkers of doping: Uses, discovery and validation. Bioanalysis, 12 (11), 791-800 (2020).

33. Loria, F. et al. Automation of rna-based biomarker extraction from dried blood spots for the detection of blood doping. Bioanalysis, 12 (11), 729-36 (2020).

34. Papadopoulos, K., Wattanaarsakit, P., Prasongchean, W. \& Narain, R. Gene therapies in clinical trialsp. 231-56(Elsevier, Polymers and Nanomaterials for Gene Therapy, 2016).

35. Chamberlain, J. R. \& Chamberlain, J. S. Progress toward gene therapy for duchenne muscular dystrophy. Mol Ther, 25 (5), 1125-31 (2017). 
36. Gonçalves, G. A. R. \& Paiva, R. M. A. Gene therapy: Advances, challenges and perspectives. Einstein (Sao Paulo), 15, 369-75 (2017).

37. Nidetz, N. F. et al. Adeno-associated viral vector-mediated immune responses: Understanding barriers to gene delivery. Pharmacol Therapeut, 207, 107453 (2020).

38. Baoutina, A., Alexander, I. E., Rasko, J. E. \& Emslie, K. R. Potential use of gene transfer in athletic performance enhancement. Mol Ther, 15 (10), 1751-66 (2007).

39. Baoutina, A. A brief history of the development of a gene doping test.Bioanalysis; 2020. 10.4155/bio2020-0056.

40. Moro, L. N. et al. Generation of myostatin edited horse embryos using crispr/cas9 technology and somatic cell nuclear transfer. Sci Rep, 10 (1), 1-10 (2020).

41. Brzeziańska, E., Domańska, D. \& Jegier, A. Gene doping in sport-perspectives and risks. Biol Sport, 31 (4), 251 (2014).

42. Neuhaus, C. P. \& Parent, B. Gene doping-in animals? Ethical issues at the intersection of animal use, gene editing, and sports ethics. Camb Q Healthc Ethic, 28 (1), 26-39 (2019).

43. Zhang, J. J. et al. Detection of exogenous gene doping of igf-i by a real-time quantitative pcr assay. Biotechnol Appl Bioc, 64 (4), 549-54 (2017).

44. Cheung, H. W., Wong, K. S., Lin, V. Y., Wan, T. S. \& Ho, E. N. A duplex qpcr assay for human erythropoietin (epo) transgene to control gene doping in horses. Drug Test Anal, 13 (1), 113-21 (2021).

45. Moser, D. A. et al. Transgene detection by digital droplet pcr. PloS One, 9 (11), e111781 (2014).

46. Wilkin, T., Baoutina, A. \& Hamilton, N. Equine performance genes and the future of doping in horseracing. Drug Test Anal, 9 (9), 1456-71 (2017).

47. Bryan, K., Katz, L. \& Hill, E. Effects of equine myostatin (mstn) genotype variation on transcriptional responses in thoroughbred skeletal muscle. Comp Exerc Physiol, 15 (5), 327-38 (2019).

48. Bailly-Chouriberry, L. et al. Rna sample preparation applied to gene expression profiling for the horse biological passport. Drug Testing Anal, 9 (9), 1448-55 (2017).

49. Hill, E. W. et al. A sequence polymorphism in mstn predicts sprinting ability and racing stamina in thoroughbred horses. PloS One, 5 (1), e8645 (2010).

50. Hill, E. W., McGivney, B. A., Gu, J., Whiston, R. \& Machugh, D. E. A genome-wide snp-association study confirms a sequence variant (g.66493737c>t) in the equine myostatin (mstn) gene as the most powerful predictor of optimum racing distance for thoroughbred racehorses. BMC genomics, 11, 552 (2010).

51. Tozaki, T. et al. A genome-wide association study for racing performances in thoroughbreds clarifies a candidate region near the mstn gene. Anim Genet, 41 (s2), 28-35 (2010).

52. Binns, M., Boehler, D. \& Lambert, D. Identification of the myostatin locus ( $m s t n)$ as having a major effect on optimum racing distance in the thoroughbred horse in the USA. Anim Genet, 41 (s2), 154-8 (2010). 
53. van den Hoven, R. et al. Putative regulation mechanism for the $m s t n$ gene by a cpg island generated by the sine marker ins227bp. BMC Vet Res, 11 (1), 1 (2015).

54. Rooney, M. F., Hill, E. W., Kelly, V. P. \& Porter, R. K. The "speed gene" effect of myostatin arises in thoroughbred horses due to a promoter proximal sine insertion. PloS One, 13 (10), e0205664 (2018).

55. Rooney, M. F., Porter, R. K., Katz, L. M. \& Hill, E. W. Skeletal muscle mitochondrial bioenergetics and associations with myostatin genotypes in the thoroughbred horse. PloS One, 12 (11), e0186247 (2017).

56. Hill, E. et al. The contribution of myostatin ( $m s t n)$ and additional modifying genetic loci to race distance aptitude in thoroughbred horses racing in different geographic regions. Equine Vet J, 51 (5), 625-33 (2019).

57. Petersen, J. L. et al. Genome-wide analysis reveals selection for important traits in domestic horse breeds. PLoS Genet, 9 (1), e1003211 (2013).

58. Petersen, J. L., Valberg, S. J., Mickelson, J. R. \& McCue, M. E. Haplotype diversity in the equine myostatin gene with focus on variants associated with race distance propensity and muscle fiber type proportions.Anim Genet. 2014. 10.1111/age.12205.

59. Rooney, M. et al. Prolonged oral coenzyme q10- $\beta$-cyclodextrin supplementation increases skeletal muscle complex i+ iii activity in young thoroughbreds. J Appl Anim Nutr, 8 (1), 11-20 (2020).

60. Yin, X. M. et al. Bid-deficient mice are resistant to fas-induced hepatocellular apoptosis., 400 (6747), 886-91 (1999).

61. Danial, N. N. et al. Bad and glucokinase reside in a mitochondrial complex that integrates glycolysis and apoptosis., 424 (6951), 952-6 (2003).

62. Blau, H. M. et al. Plasticity of the differentiated state., 230 (4727), 758-66 (1985).

63. Green, H. \& Meuth, M. An established pre-adipose cell line and its differentiation in culture., 3 (2), 127-33 (1974).

64. Green, H. inventorTriglyceride-accumulating clonal cell line. United States patent US1977 Jan 18.

65. Young, L., Sung, J., Stacey, G. \& Masters, J. R. Detection of mycoplasma in cell cultures. Nature Protoc, 5 (5), 929-34 (2010).

66. Hill, E. W. et al. Mstn genotype (g.66493737c/t) association with speed indices in thoroughbred racehorses. J Appl Physiol, 112 (1), 86-90 (2012).

67. Macpherson, P. C., Suhr, S. T. \& Goldman, D. Activity-dependent gene regulation in conditionallyimmortalized muscle precursor cell lines. J Cell Bioc, 91 (4), 821-39 (2004).

68. Jacobsen, F. et al. Polybrene improves transfection efficacy of recombinant replication-deficient adenovirus in cutaneous cells and burned skin. J Gene Med, 8 (2), 138-46 (2006).

69. Di Donna, S. et al. Telomerase can extend the proliferative capacity of human myoblasts, but does not lead to their immortalization. Mol Cancer Res, 1 (9), 643-53 (2003).

70. Oh, H-Y. et al. Characteristics of primary and immortalized fibroblast cells derived from the miniature and domestic pigs. BMC Cell Biol, 8 (1), 20 (2007). 
71. Smith, P. K. et al. Measurement of protein using bicinchoninic acid. Anal Bioc, 150 (1), 76-85 (1985).

72. Srere, P. A.. [1] citrate synthase: [ec 4.1.3.7. Citrate oxaloacetate-lyase (coa-acetylating)]. In: John ML, editor. Methods in enzymology. Volume 13:Academic Press; 1969.p. 3-11

73. Powers, W. J. et al. Normal platelet mitochondrial complex i activity in huntington's disease. Neurobiol Dis, 27 (1), 99-101 (2007).

74. Zhu, C. H. et al. Cellular senescence in human myoblasts is overcome by human telomerase reverse transcriptase and cyclin-dependent kinase 4 : Consequences in aging muscle and therapeutic strategies for muscular dystrophies., 6 (4), 515-23 (2007).

75. Rokach, O. et al. Establishment of a human skeletal muscle-derived cell line: Biochemical, cellular and electrophysiological characterization. Bioc J, 455 (2), 169-77 (2013).

76. Stadler, M. \& Fire, A. Wobble base-pairing slows in vivo translation elongation in metazoans. RNA, 17 (12), 2063-73 (2011).

77. Muses, S., Morgan, J. E. \& Wells, D. J. A new extensively characterised conditionally immortal muscle cell-line for investigating therapeutic strategies in muscular dystrophies. PloS One, 6 (9), e24826 (2011).

78. Thorley, M. et al. Skeletal muscle characteristics are preserved in htert/cdk4 human myogenic cell lines. Skelet Muscle, 6 (1), 1-12 (2016).

79. Yaffe, D. Retention of differentiation potentialities during prolonged cultivation of myogenic cells. $P$ Natl Acad Sci USA, 61 (2), 477 (1968).

80. Wang, Z. Y., Paris, L. L., Chihara, R. K., Tector, A. J. \& Burlak, C. Immortalized porcine liver sinusoidal endothelial cells: An in vitro model of xenotransplantation-induced thrombocytopenia., 19 (4), 24955 (2012).

81. Balducci, L. et al. Immortalization of human adipose-derived stromal cells: Production of cell lines with high growth rate, mesenchymal marker expression and capability to secrete high levels of angiogenic factors. Stem Cell Res Ther, 5 (3), 63 (2014).

82. Olyslaegers, D. A., Desmarets, L. M., Dedeurwaerder, A., Dewerchin, H. L. \& Nauwynck, H. J. Generation and characterization of feline arterial and venous endothelial cell lines for the study of the vascular endothelium. BMC Vet Res, 9 (1), 170 (2013).

83. Ahn, J. S. et al. Ectopic overexpression of porcine myh1 increased in slow muscle fibers and enhanced endurance exercise in transgenic mice. Int J Mol Sci, 19 (10), 2959 (2018).

84. Tozaki, T. et al. Sequence variants at the myostatin gene locus influence the body composition of thoroughbred horses. J Vet Med Sci, 73 (12), 1617-24 (2011).

85. Porter, R. K. \& Brand, M. D. Cellular oxygen consumption depends on body mass. Am J Physiol, 269 (1 Pt 2), R226-8 (1995).

86. Nicholls, D. G. et al. Bioenergetic profile experiment using c2c12 myoblast cells.JoVE - J Vis Exp. 2010(46):e2511. 10.3791/2511. 
87. Skala, M. C. et al. In vivo multiphoton microscopy of nadh and fad redox states, fluorescence lifetimes, and cellular morphology in precancerous epithelia. P Natl Acad Sci, 104 (49), 19494-9 (2007).

88. Okkelman, I. A., Neto, N., Papkovsky, D. B., Monaghan, M. G. \& Dmitriev, R. I. A deeper understanding of intestinal organoid metabolism revealed by combining fluorescence lifetime imaging microscopy (flim) and extracellular flux analyses. Redox Biol, 30, 101420 (2020).

89. Neto, N., Dmitriev, R. I. \& Monaghan, M. G. Seeing is believing: Noninvasive microscopic imaging modalities for tissue engineering and regenerative medicine.Cell Engineering and Regeneration. 2020:599-638. 10.1007/978-3-319-08831-0_40.

90. Walsh, A. J. et al. Classification of t-cell activation via autofluorescence lifetime imaging. Nature Biomed Eng, 5 (1), 77-88 (2021).

91. Quinn, K. P. et al. Characterization of metabolic changes associated with the functional development of $3 \mathrm{~d}$ engineered tissues by non-invasive, dynamic measurement of individual cell redox ratios., 33 (21), 5341-8 (2012).

92. Meleshina, A. V. et al. Two-photon flim of nad ( $p) h$ and fad in mesenchymal stem cells undergoing either osteogenic or chondrogenic differentiation. Stem Cell Res Ther, 8 (1), 1-10 (2017).

93. Huang, S., Heikal, A. A. \& Webb, W. W. Two-photon fluorescence spectroscopy and microscopy of nad (p) h and flavoprotein. Biophys J, 82 (5), 2811-25 (2002).

94. Bonetti, A., Solito, F., Carmosino, G., Bargossi, A. \& Fiorella, P. Effect of ubidecarenone oral treatment on aerobic power in middle-aged trained subjects. J Sport Med Phys Fit, 40 (1), 51 (2000).

95. Cooke, M. et al. Effects of acute and 14-day coenzyme q10 supplementation on exercise performance in both trained and untrained individuals. J Int Soc Sport Nutr, 5 (1), 1 (2008).

96. Mizuno, K. et al. Antifatigue effects of coenzyme q10 during physical fatigue. Nutrition, 24 (4), 2939 (2008).

97. Alf, D., Schmidt, M. E. \& Siebrecht, S. C. Ubiquinol supplementation enhances peak power production in trained athletes: A double-blind, placebo controlled study. J Int Soc Sport Nutr, 10 (1), 1-8 (2013).

98. Leelarungrayub, D., Sawattikanon, N., Klaphajone, J., Pothongsunan, P. \& Bloomer, R. J. Coenzyme q10 supplementation decreases oxidative stress and improves physical performance in young swimmers: A pilot study.Sports Med. 2010; 4(1). 10.2174/1874387001004010001.

99. Laemmli, U. K. Cleavage of structural proteins during the assembly of the head of bacteriophage t4., 227 (5259), 680-5 (1970).

\section{Figures}




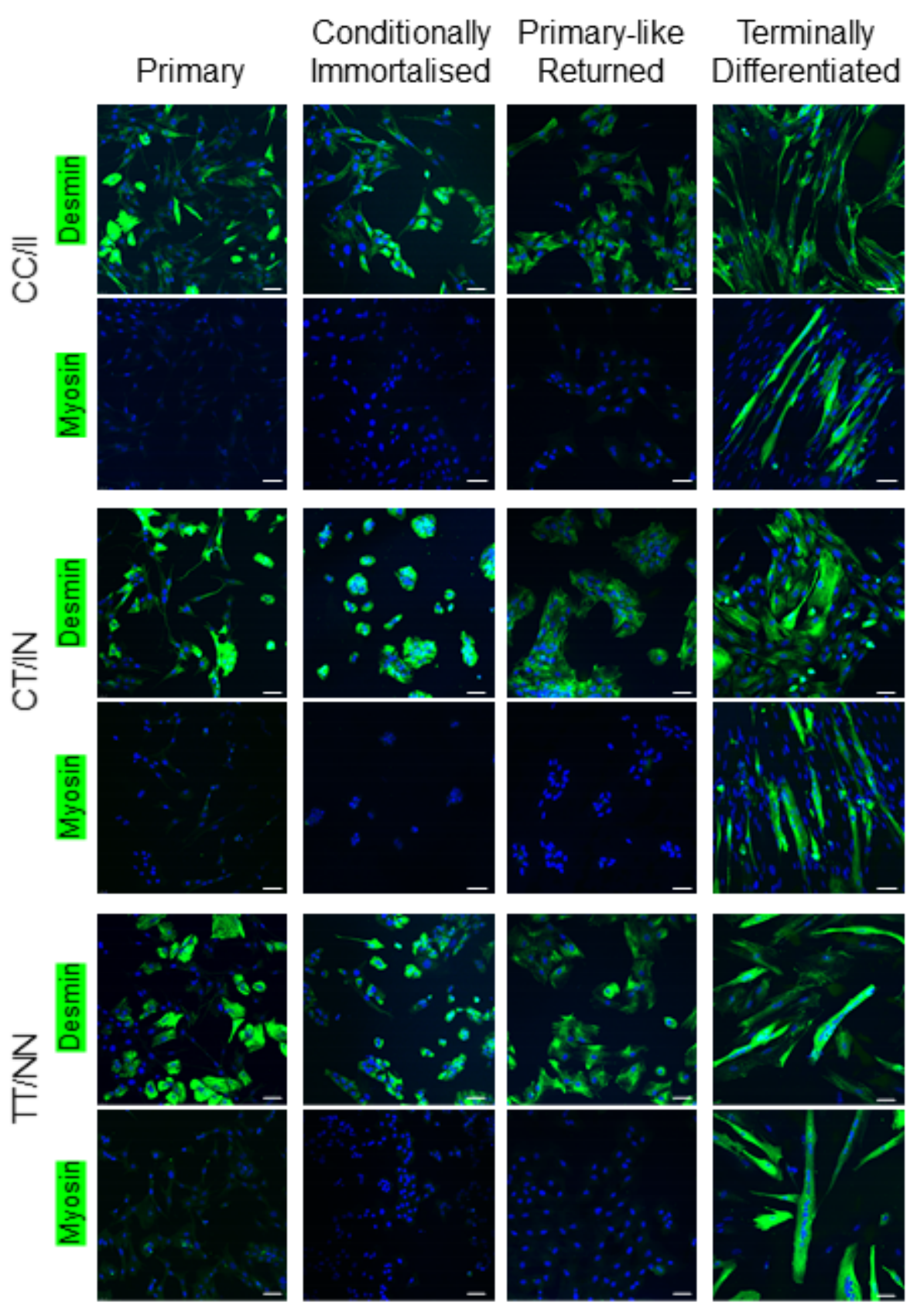

Figure 1

Desmin and sarcomeric myosin expression in equine skeletal muscle cells: Immunofluorescence images of Thoroughbred skeletal muscle; primary, conditionally immortalized, and primary-like myoblasts and terminally differentiated myotubes from three MSTN (CC/II, CT/IN, TT/NN) genotypes. Green, desmin (myogenic marker)/sarcomeric myosin (myosin) (differentiation marker); blue, nuclei. Images were take using a Leica SP8 confocal microscope at 20X. Scale bar (white) indicates $50 \mu \mathrm{M}$. Each image is representative of at least 3 independent experiments. 
A

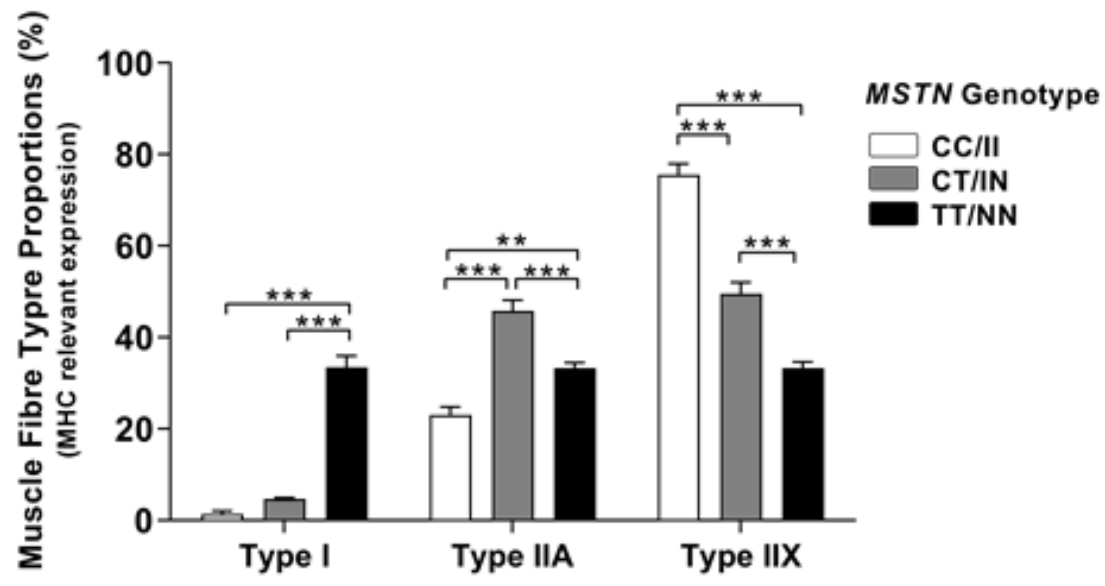

B

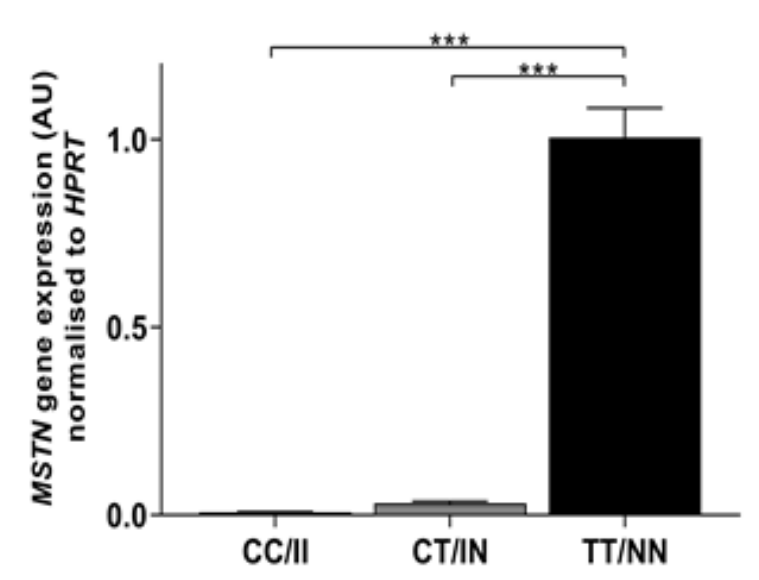

C

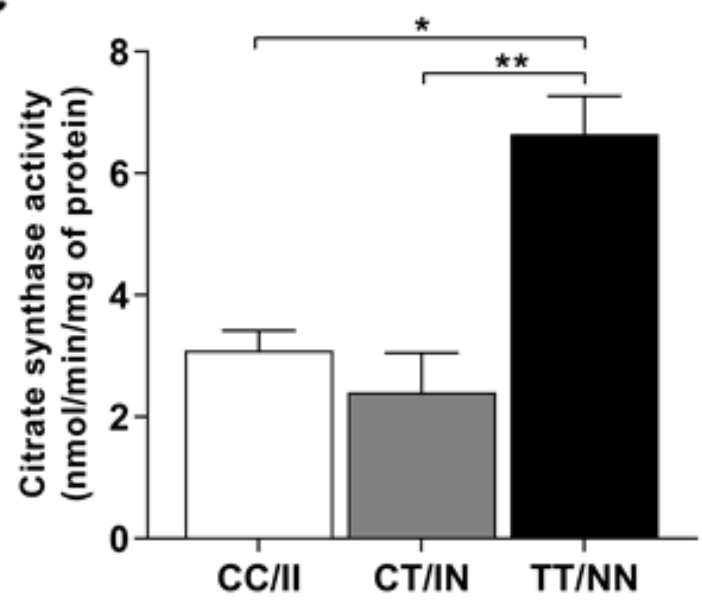

D

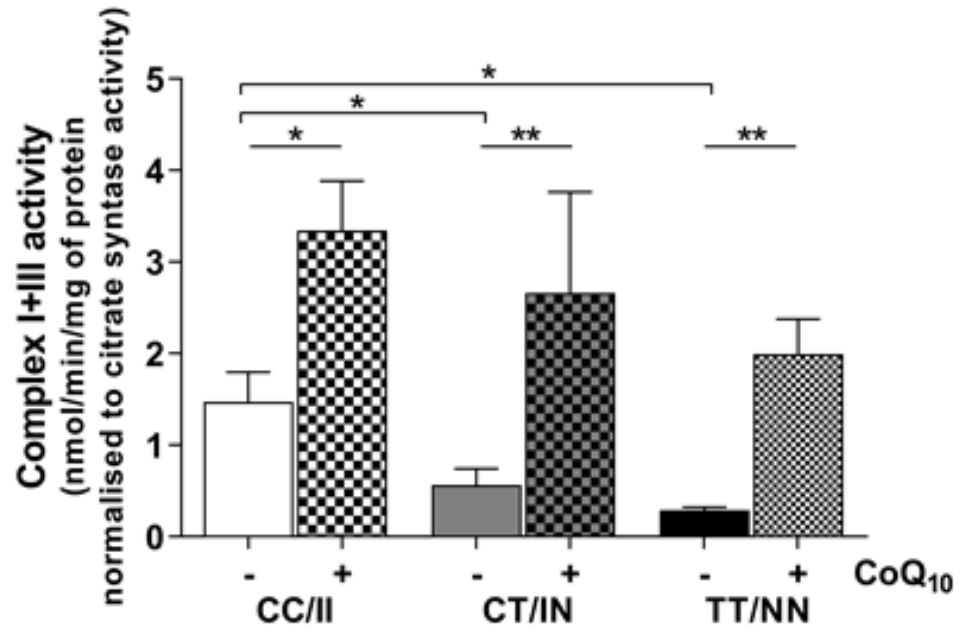

Figure 2

Fibre proportions, MSTN gene expression, Mitochondrial abundance and CoQ10 content of immortalized equine myotubes: (A-D) Phenotypes compared among three MSTN genotype cell lines, CC/II (white); $\mathrm{CT} / \mathrm{IN}$ (grey) and TT/NN (black). (A) qPCR was used to measure gene expression levels of: MYH7, MYH2 and MYH1 inferring MHC isoforms and interpreted as Type I, Type IIA and Type IIX fibres, respectively, expressed as relative percentage of total MHC gene expression. (B) MSTN gene expression was 
measured by qPCR, normalised to HPRT using the $\triangle \triangle \mathrm{Ct}$ method. (C) Mitochondrial abundance determined by the activity of citrate synthase measured spectrophotometrically, expressed as $\mathrm{nmol} / \mathrm{min} / \mathrm{mg}$ of muscle protein. (D) NADH cytochrome c oxidoreductase (Complex I + III) activity, as an indirect measure of CoQ (ubiquinone), measured spectrophotometrically and expressed as $\mathrm{nmol} / \mathrm{min} / \mathrm{mg}$ of muscle protein, normalised to citrate synthase activity. - (plain bars) and + CoQ10 (5 $\mu \mathrm{M}$ for 24 hours) treated (dotted bars) samples, were analysed. (A-D) Results presented with mean \pm SEM $(N=3$ per genotype, performed in triplicate technical replicates), p-values where shown indicate significance as measured by; a two-way $(A, D)$ or one-way $(B, C)$ ANOVA with a Tukeys multiple comparisons test * $=p \leq$ $0.05, * \star=p \leq 0.01, * \star \star=p \leq 0.001$. 

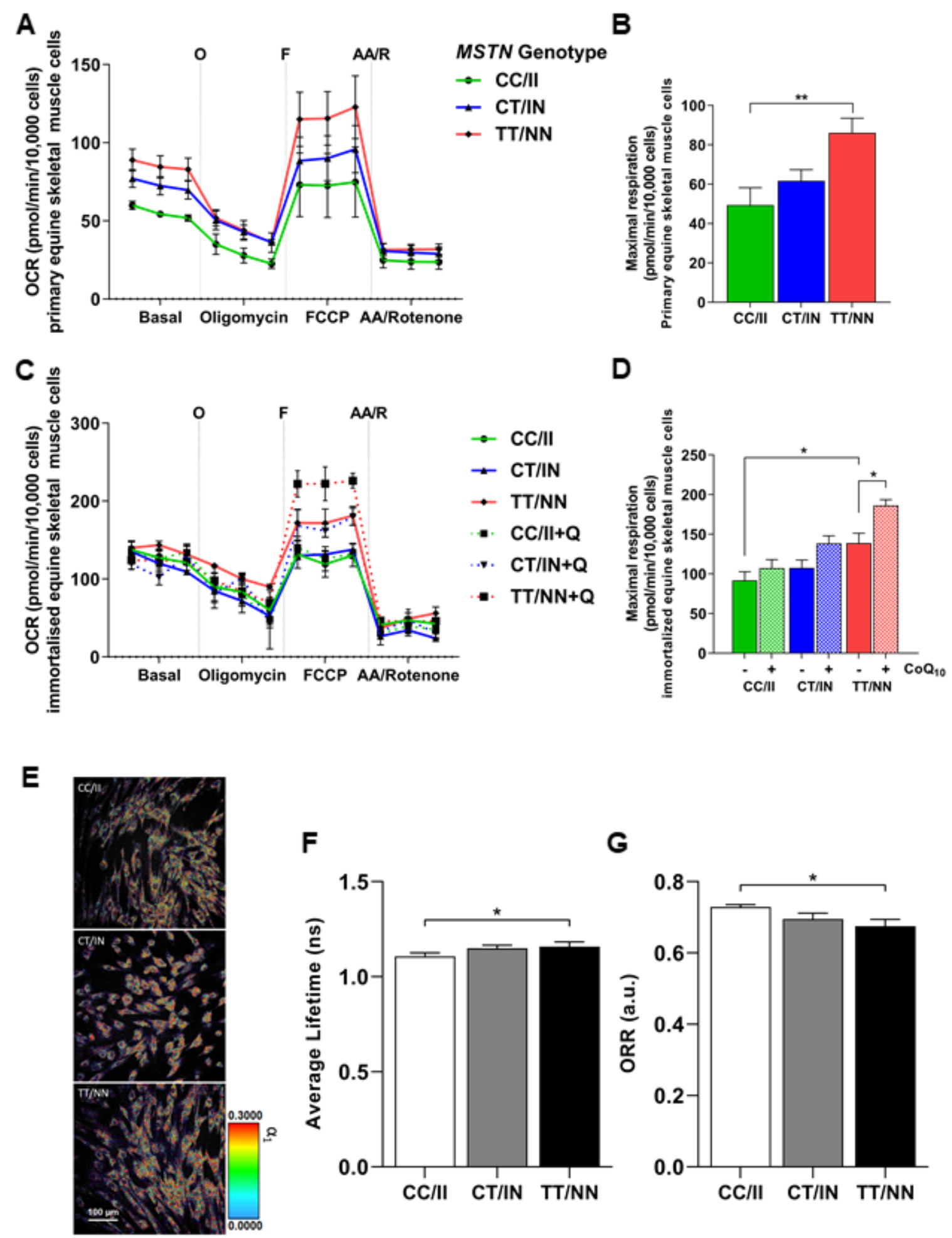

\section{Figure 3}

Cellular respiration and oxidative metabolism: (A-D) Cellular oxygen consumption rates (OCR), determined by Seahorse XFp Extracellular Flux analyser. Mitochondrial inhibitors/uncouplers were added sequentially during the experiment in the following concentrations: oligomycin $1 \mu \mathrm{M}(0)$, FCCP $1 \mu \mathrm{M}(\mathrm{F})$ and antimycin A/rotenone $0.5 \mu \mathrm{M}(\mathrm{AA} / \mathrm{R})$. MSTN genotypes; CC/II (green), CT/IN (blue) and TT/NN (red); (A) OCR of primary equine skeletal muscle cells; (B) maximal respiration (maximum rate measurement 
after FCCP injection) - (non-mitochondrial respiration after AA/R injection) primary equine skeletal muscle cells; (C) OCR of immortalized equine skeletal muscle cells; - and + CoQ10 (5 $\mu \mathrm{M}$ for 24 hours); (D) maximal respiration immortalized equine skeletal muscle cells, - (plain bars) and + CoQ10 (5 $\mu \mathrm{M}$ for 24 hours) (dotted bars). (E-G) FLIM analysis of the immortalised cell lines (NAD(P)H-FLIM imaging; marker of oxidative metabolism); (E) average lifetime (ns); (F) optical redox ratio (a.u.); (G) NAD(P)H-FLIM images, each image is representative of 3 independent experiments. Results presented with mean \pm SEM ( $N=3$ per genotype, performed in triplicate technical replicates), $p$-values where shown indicate significance as measured by; a one-way (B, E, F) or two-way (D) ANOVA with a Tukeys multiple comparisons test $*=p \leq 0.05,{ }^{* *}=p \leq 0.01,{ }^{* \star *}=p \leq 0.001$.

\section{Supplementary Files}

This is a list of supplementary files associated with this preprint. Click to download.

- SupplementalFiles.pdf 